
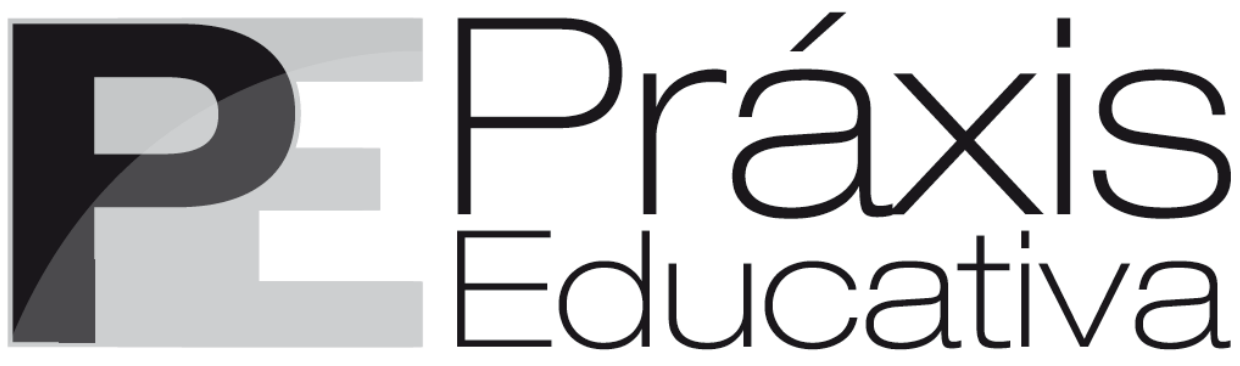

ISSN 1809-4309 (Versão online)

DOI: 10.5212/PraxEduc.v.11i3.0024

\title{
ALMEIDA FILHO, José Carlos Paes de. Fundamentos de abordagem e formação no ensino de PLE e de outras línguas. Campinas: Pontes Editores, 2011. $130 \mathrm{p}$.
}

\author{
Juliana Paiva Santiago* \\ Rosemeire Monteiro-Plantin ${ }^{* *}$
}

Um dos precursores na literatura da ascendente área de ensino-aprendizagem de Português Língua Estrangeira (PLE), José Carlos Paes de Almeida Filho, renova-se em sua importante militância, lançando pela Pontes Editores, no ano de 2011, Fundamentos de abordagem e formação no ensino de PLE e de outras línguas.

A coletânea organizada pelo professor da Universidade de Brasília (UnB), constituída por oito artigos autorais, sendo dois deles (os capítulos dois e quatro) elaborados em parceria com o professor da Universidade de Macau, Ricardo Moutinho, direciona-se a professores de línguas estrangeiras, mas, em especial, a docentes de PLE em qualquer estágio de sua formação e carreira.

De leitura simples e fluida, revela-se um verdadeiro manual amplamente voltado àqueles que almejam despertar para a reflexão, a percepção e a inovação da prática docente do ensino de língua estrangeira e cujos méritos são atribuídos pelo autor aos professores de PLE das cidades de Bogotá, Manágua, Assunção e Lima, que leram e debateram em prol da edificação dessa obra. Por meio da abordagem de questões que vão desde a ação à autoavaliação docente, perpassando pelo contexto atual de planejamento, de políticas linguísticas, de relações interculturais, o PLE se revela como tema cada vez mais eminente no cenário nacional e mundial. Dessa forma, Almeida Filho marca suas entrelinhas com forte esmero em prol da qualidade e da criticidade do profissional de LE.

Os temas são abordados de modo a gerar profundas reflexões no docente com vistas a elucidá-lo acerca da importância do seu papel político e social na construção de saberes com e por meio da língua por ele apresentada, conscientizando-o, por conseguinte, da sua carga identitária e cultural indissociável nela presente. Para tanto, cada capítulo dispõe, ao final, de um apêndice com questões sobre o tema anteriormente tratado, a fim de auxiliar o leitor a retomar criticamente seu conteúdo.

\footnotetext{
* Mestre em Linguística pela Universidade Federal do Ceará (UFC). E-mail: < julisantiago.jps@gmail.com>.

${ }^{* *}$ Doutora em Linguística pela Universidade Federal de Santa Catarina (UFSC). Professora da Universidade Federal do Ceará (UFC). E-mail: <meire@ufc.br>.
}

Práxis Educativa, Ponta Grossa, p. 926-928, v. 11, n. 3, set./dez. 2016 Disponível em: <http://www.revistas2.uepg.br/index.php/praxiseducativa> 
No primeiro capítulo, intitulado Ensino - aprendizagem de Português como LE e L2: Fundamentos de abordagem e formação, Almeida Filho tenciona, a partir do acompanhamento do Programa de Formação Integral Continuada de Professores de Português como Língua Não Materna (PROFIC), elucidar acerca da dimensão da prática do docente em PLE, refletir sobre os mais proveitosos caminhos em sala de aula para professores nativos e não-nativos, assim como estabelecer a diferença entre formação docente e ensino de línguas propriamente dito. Nesse capítulo, o autor argumenta, ainda, acerca da importância de oferecer teorias formais aos docentes de línguas, tais como a apresentação de filosofias específicas de ensino-aprendizagem, métodos, abordagens, técnicas e recursos para que assim possam dar origem a uma prática pautada no conhecimento crítico e orientada à contínua reflexão.

No segundo capítulo, Sentidos de ensinar PLE no mundo, discute-se o forte caráter representacional do Português Brasileiro como língua de cultura e identidade e seu perfil atual no cenário global: políticas de implantação de cursos, demanda da língua, questões de afetividade e rejeição, e o quadro atual de ensino de PLE. Ainda sob o mesmo eixo, reflete-se sobre o papel do professor nativo como representante da cultura brasileira, atentando para a importância de prezar pelo ensino das variantes e a fuga de estereótipos com vistas a elucidar os discentes acerca da heterogeneidade cultural brasileira.

Ensinar uma nova língua para aquisição, o terceiro capítulo, advoga por uma metodologia na qual possa ocorrer a aquisição, considerado meio natural de dominar uma língua. Nesse sentido, o autor relembra algumas correntes de ensino e de aprendizagem dos anos de 1970 nas quais se punham o enfoque humanista e o gramatical em oposição, no intento de plantear questionamentos no que tange ao ensino para a reflexão, ao contexto propício para haver aquisição por parte dos aprendizes, ao filtro afetivo e aos agentes que influenciam a aprendizagem. $\mathrm{O}$ autor sugere, por conseguinte, uma proposta na qual haja uma mescla de enfoques, em outras palavras, a sistematização da língua adquirida.

O capítulo quatro, Aprender PLE na Universidade, inicia direcionando o leitor a pensar sobre a aprendizagem de línguas sob o contexto de avanços tecnológicos, globalização e abertura de mercados provenientes do MERCOSUL e negociações com os países do BRICS (Brasil, Rússia, Índia, China e África do Sul). Propõe-se, assim, situar o ensino de PLE em constante expansão dentro desse panorama, e, a partir de então, discutir a implantação e o planejamento de cursos de PLE nas universidades. Ainda, nessa perspectiva, discute-se como justificar o ensino de PLE e como descentralizá-lo da norma padrão a fim de difundir sua heterogeneidade.

Em Gramática no Ensino de Linguas, quinto capítulo, Almeida Filho pondera sobre a questão da Língua como matéria, na qual se descreve e se explana sua gramática e, nesse sentido, afirma não haver interface entre a aquisição da capacidade de uso fluente de uma língua e seu ensino com foco na gramática dessa língua. Em defesa da tendência ao enfoque comunicativo, o autor lança mão de ideias de um ensino no qual a explicitação gramatical esteja presente, porém, em decorrência do uso comunicacional do idioma, prezando, assim, pela ênfase comunicacional em detrimento da ortodoxia da explanação gramatical e de um aumento qualitativo da aquisição linguística.

Já, o sexto capítulo, Ensino de Português Lingua Estrangeira: a emergência de uma área, objetiva, segundo o autor, "[...] abrir uma cronologia periodizada de fatos e personagens relevantes para esboçar os contornos de uma história do PLE enquanto campo de trabalho e especialidade acadêmico - científica no país, desde a fundação do Brasil até a data desta publicação" (ALMEIDA FILHO, 2011, p. 94). O capítulo trata do recente reconhecimento da profissão do docente de línguas; traça um panorama histórico que percorre a época colonial, passando pelo lançamento dos primeiros livros teóricos de ensino-aprendizagem de línguas, chegando à 
coletânea coordenada por Almeida Filho, literatura pioneira no Brasil e em Portugal, abordando aspectos do ensino de Português para falantes de outras línguas; cita importantes acontecimentos, tais como o incentivo de ações referentes à língua portuguesa advindo do MERCOSUL e a criação do exame de proficiência em PLE, Celpe-Bras; e, finalmente, faz um balanço de problemas que ainda permanecem e propostas que poderiam vir a ser implantadas visando uma melhoria no quadro vigente.

Ao questionar qual seria o lugar do aspecto cultural no ensino-aprendizagem de LE, o artigo, publicado pela primeira vez em 2002 e agora compondo o capítulo sete, Lingua além da cultura ou além da cultura: língua, aspectos do ensino da interculturalidade, traz a reflexão sobre o espaço do aspecto cultural no processo de aquisição, nos livros didáticos, nas referências apresentadas pelo docente, bem como volta a indagar de que maneira são explorados os tópicos culturais e como o Brasil é representado por meio dos vários agentes que influenciam o processo de ensinoaprendizagem de LE.

Finalmente, o último capítulo, Tendências atuais no ensino de línguas, traz uma temática imprescindível à proposta dessa obra: a revisitação das distintas tendências na área de aquisição, aprendizagem e ensino de idiomas. $\mathrm{O}$ autor lista três agentes do processo de aprendizagem, assim como o grau de interferência, papel e atuação desses elementos. O primeiro agente configura-se como os alunos. O professor, classificado como segundo agente, deve embasar sua ação profissional por uma filosofia pautada não só em teorias de aprendizagem, mas também em práticas, crenças e necessidades dos alunos. Coordenadores, diretores, pais de alunos e autores de materiais didáticos são listados como o terceiro agente, cuja atuação costuma ser indireta. Além da discussão sobre os agentes, o planejamento de ensino, os objetivos, os materiais e os métodos utilizados em sala de aula, as extensões das aulas e a avaliação são questionadas e repensadas juntamente à atuação do professor, em favor de uma ação plenamente consciente em sala de aula.

Da redação aos apêndices, atravessados por referências de sítios na web, esquemas gráficos e obras da literatura especializada, Fundamentos de abordagem e formação no ensino de PLE e de outras linguas dialoga com o professor em formação, convidando-o a pensar o fazer docente revitalizado a cada capítulo, apresentando novas mídias, revigorando antigos conhecimentos, propondo novos caminhos de pesquisa e ensejando descobertas por entre suas 130 páginas.

Práxis Educativa, Ponta Grossa, p. 926-928, v. 11, n. 3, set./dez. 2016 Disponível em: <http://www.revistas2.uepg.br/index.php/praxiseducativa> 